\title{
Topography of the common fibular nerve terminal division in human foetuses
}

\author{
A. Karykowska1', Z.A. Domagała2(1), B. Gworys ${ }^{3}$ (D) \\ ${ }^{1}$ Department of Anthropology, Wroclaw University of Environmental and Life Sciences, Wroclaw, Poland \\ 2Division of Anatomy, Department of Human Morphology and Embryology, Faculty of Medicine, \\ Wroclaw Medical University, Wroclaw, Poland \\ ${ }^{3}$ Faculty of Health Science and Physical Education, The Witelon State University of Applied Sciences, Legnica, Poland
}

[Received: 30 May 2020; Accepted: 12 August 2020; Early publication date: 2 September 2020]

Background: The progress of paediatric surgery and increasingly better diagnosis of foetal defects require detailed knowledge of human developmental anatomy. Precise knowledge of the anatomy of innervation of the lower extremities corresponds to this subject and is not only cognitive but also clinically important. The end of the common fibular nerve is superficially located in the area exposed to frequent injuries as well as in the area subject to possible surgical repair procedures. Materials and methods: The analysis was carried out on 200 human foetuses aged from the $113^{\text {th }}$ day to $222^{\text {nd }}$ day of foetal life. The study material is a part of local foetal collection. The study incorporated the following methods: anthropological, preparational and image acquisition which was acquired with the use of high-resolution digital camera. Statistical analysis was carried out with the use of STATISTICA package.

Results: Based on the research results the new typology of the examined nerve was determined. The head of the fibula was the criterion: (i) high division - above the head of the fibula (1\%); (ii) intermediate division - at the height of the head of the fibula (34\%); (iii) low division - below the head of the fibula (65\%). The mathematical analysis did not reveal statistically significant bilateral and gender differences. Moreover the additional branch was observed in 30\% of foetuses, regardless of age class. This branch occurred in $50 \%$ of cases in both sides of the foetus. This nerve was defined as the accessory fibular nerve (nervous fibularis/ peroneus accessorius).

Conclusions: The created unique typology of the terminal division of common fibular nerve is an important supplement to the anatomical knowledge and at the same time, due to the peripheral and superficial location of the described structures, it has a relatively high clinical significance. (Folia Morphol 2022; 81, 1: 37-43)

Key words: common peroneal nerve, dissection, human foetuses, accessory fibular nerve

\section{INTRODUCTION}

The common fibular nerve (nervus peroneus communis) is formed as a branch of the sciatic nerve (nervus ischiadicus) at thigh level or in the area of the popliteal fossa $[37,38]$. It runs in the distal and lateral direction, towards the head of the fibula. It then bends around the fibula neck (collum fibulae) and divides into superficial and deep fibular nerves 
(nervus peroneus superficialis et profundus) within the fibularis longus muscle (musculus peroneus longus) belly $[3,34,38]$. Both nerves, which are branches of the common fibular nerve, supply the anterior and lateral compartment of the leg and dorsal foot structures $[7,8,38]$. Many articles in the scientific literature have highlighted diseases and injuries to these nerves and their branches. One of the most common postoperative complications in the leg area is neuroma of the common or superficial fibular nerve $[4,6,22,32]$. Damage to the common fibular nerve and its branches as a result of fibula fracture or superficial sports injuries are also frequent $[1,8,38]$. In addition, there are often various medical procedures carried out in the area near to the nerve trunk, which may cause iatrogenic damage to the nerve or its final branches $[2,19,21,41]$. Therefore, it is of anatomical and clinical importance to know the variability of the final division of the common fibular nerve (FDCFN).

The course, branching pattern, and relationships of the common fibular nerve and its terminal branches with bony landmarks have been well demonstrated in adults by many authors $[5,11,12,25,37,38]$. However, no information has yet been identified that would indicate a detailed bifurcation topography pattern in the foetus, which may be important in tumour surgery and treatment of early deformities [16, 29, 33, 36]. Therefore, the aim of this study was to develop a typology of the FDCFN in relation to the head of the fibula based on the available foetal material.

\section{MATERIALS AND METHODS}

Preparatory analysis was performed on 200 human foetuses aged from 113 to 222 days of foetal life. Foetal specimens were divided into age classes based on lunar months (Table 1).

The analysed foetal material comes from the collection of the Department of Anatomy in Wroclaw, Poland. It was obtained from maternity wards of local gynaecological clinics as a result of preterm and early deliveries and miscarriages between 1960 and 1996. The foetuses were stored in a suitable preservative solution containing ethanol, glycerol, and formalin in constant proportions [18, 31, 42]. Foetuses with visible developmental malformations and those that did not have complete clinical documentation were excluded from the study. The value of the foetal collection was confirmed in numerous previously published scientific studies $[10,13,14,17,18,24$, 40]. The scientific experience of the team has been
Table 1. The quantity of examined foetuses in subsequent age classes with the gender division

\begin{tabular}{lccc}
\hline Calendar age [months] & N & Males & Females \\
\hline $4+5$ & 69 & 34 & 35 \\
6 & 78 & 39 & 39 \\
7 & 40 & 18 & 22 \\
$8+9$ & 13 & 8 & 5 \\
\hline
\end{tabular}

confirmed in many works using anatomical scientific methodology and anatomical techniques used for statistical analysis $[9,15,27]$.

The preparation was performed using classical preparatory methods. In order to visualise the FDCFN, it was necessary to use the binocular surgical microscope Leica Provido (Leica Microsystems, Germany).

The prepared common fibular nerve and its two final branches were described using schematic drawings. In addition, photographs were taken using a Sony Alpha (Sony Corporation, Japan) camera and a suitable Manfrotto (Manfrotto, Italy) tripod to ensure that the angle and height of the lens in relation to the foetuses were constant.

\section{Statistical analysis}

The mean values and standard deviations ( $\pm S D$ ), minimum and maximum variability range were determined on the basis of the collected research material. In order to examine the independence of two qualitative features, the $\chi^{2}$ independence test was applied. All analyses were performed using the STATISTICA 10.0 (TIBCO Software Inc., USA) package. The work and whole study protocol was approved by the Bioethics Committee No. KB-708/2017

\section{RESULTS}

Based on sectional studies, three types of FDCFN positions were determined. The head of the fibula was the criterion: (i) type A: high division - above the head of the fibula (Fig. 1); (ii) type B: intermediate division - at the height of the head of the fibula (Fig. 2); (iii) type C: low division - below the head of the fibula (Fig. 3). Prevalence of individual types is shown in Figure 4.

The following concepts have been introduced: symmetrical division, which means that in the case of both limbs the division of the common fibular nerve into terminal branches occurs at the same level; adjacent division, which means that from one extremity 


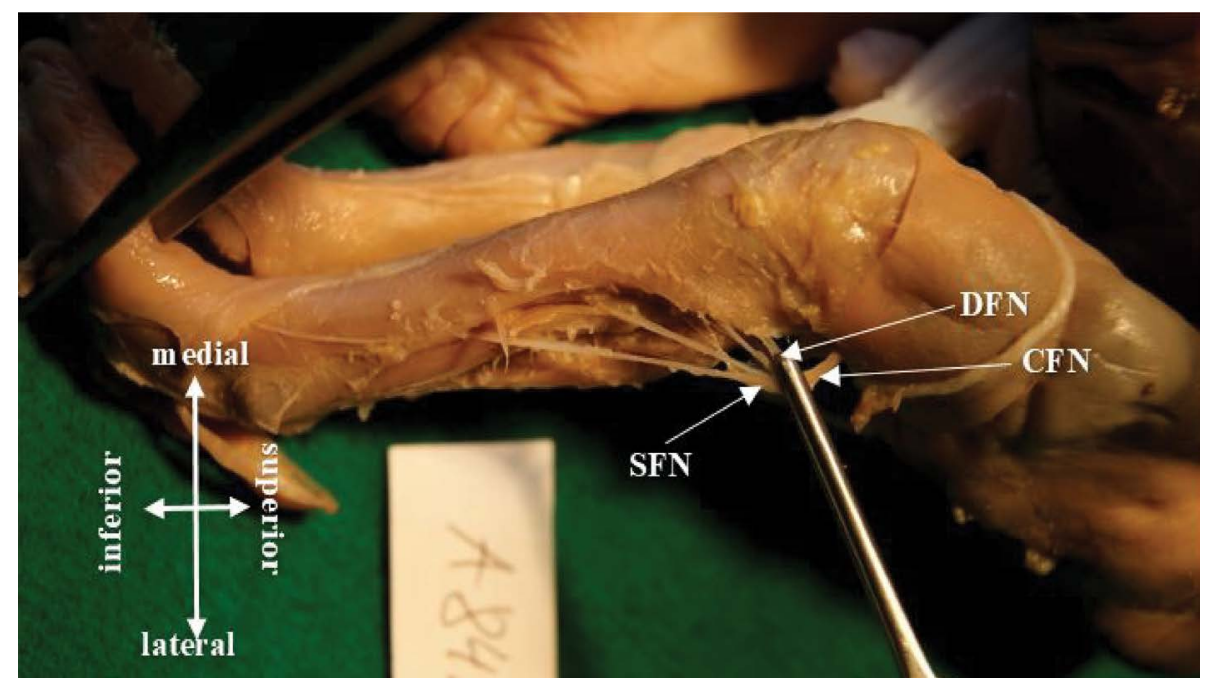

Figure 1. Type high of the common fibular nerve final division; DFN — deep fibular neve; CFN — common fibular nerve; SFN — superficial fibular nerve.

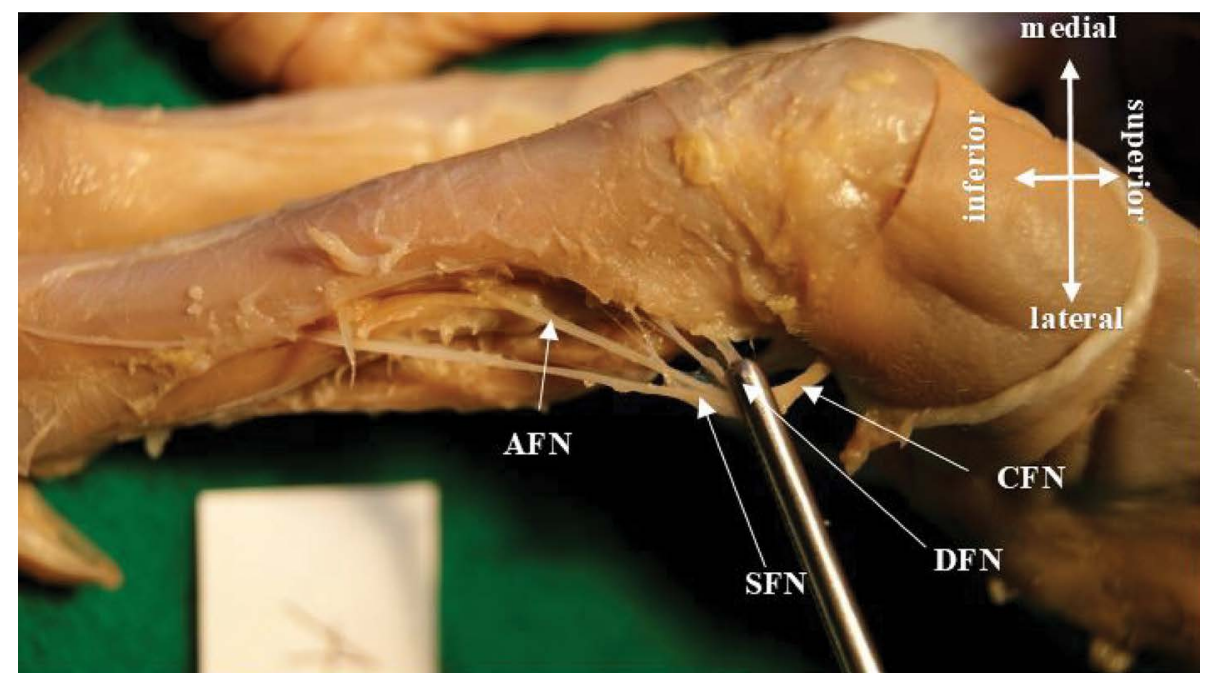

Figure 2. Intermediate type; DFN — deep fibular neve; CFN — common fibular nerve; SFN — superficial fibular nerve; AFN — accessory fibular nerve.

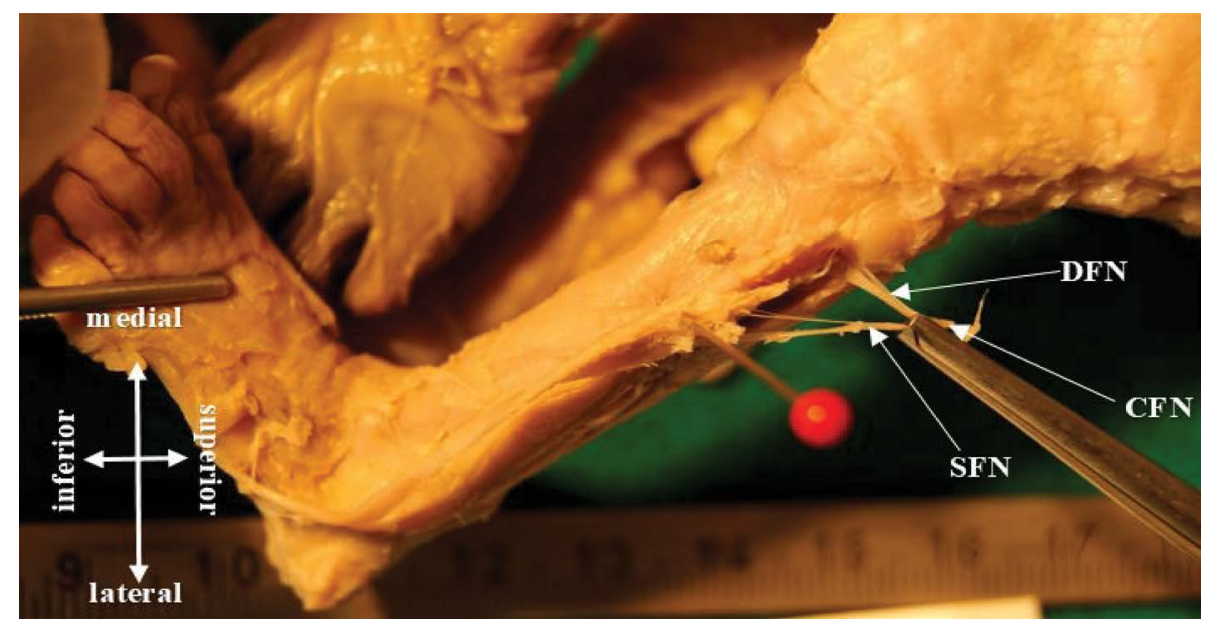

Figure 3. Low type; DFN — deep fibular neve; CFN — common fibular nerve; SFN — superficial fibular nerve. 


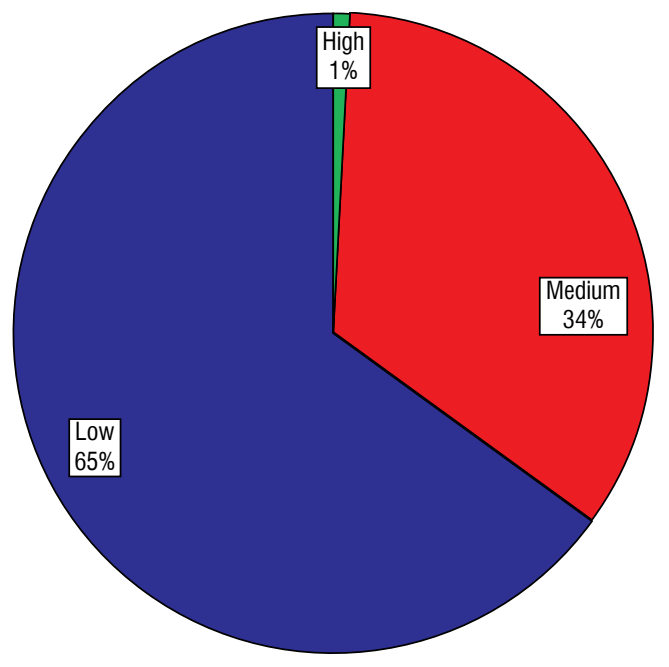

Figure 4. Percentage of individual types of end division of the examined nerve.

there is, e.g. high division, and intermediate division into the other extremity; and distant division, which refers to the extreme opposite position of the final nerve division on both limbs of one specimen (Table 2). Despite the examples of asymmetry shown (Table 2), analysis did not reveal statistically significant differences $\left(\chi^{2}=30.67, p=0.43\right)$, which means that there are no branch variants observed more frequently in particular age classes. Additionally, there was no asymmetry in the occurrence of FDCFN branches $\left(\chi^{2}=6.67, p=0.15\right)$ and no relationship between symmetrical/adjacent and distant division and foetal sex (Table 3).

A more detailed evaluation of the data showed no statistically significant differences in the right limb final division of the common fibular nerve $(p=0.21)$. Similarly, no statistically significant differences were found for the left limb $(p=0.06)$. A schematic drawing was also created for the right and left common fibular nerve, illustrating the course of this nerve and its division into subsequent branches.

Along with the superficial and deep fibular branches of the common fibular nerve, an additional branch was observed in $30 \%$ of foetuses, regardless of age class. This branch occurred in $50 \%$ of cases in both sides of the foetus. This nerve was defined as the accessory fibular nerve (nervus fibularis/peroneus accessorius) in a previous work [12]. Statistical analysis did not reveal any bilateral $(p=0.07)$ or dimorphic differences $(p=0.16)$ in the incidence of that additional branch of common fibular nerve in human foetuses.

\section{DISCUSSION}

The present work is based on unique material of high cognitive value $[17,23]$. An important novelty of this analysis is the evaluation of variability of the FDCFN based on extensive foetal material, which is difficult to obtain. The available literature analysing the subject area is relatively poor in the case of foetal

Table 2. Frequency of occurrence of particular types of common fibular nerve terminal division (FDCFN) in selected age classes and symmetry of occurrence of given types depending on the age class

\begin{tabular}{lcccccccc}
\hline Month & A + B & A + C & B + A & B + B & B + C & C + B & C + C & Total \\
\hline $4+5$ & 0 & 0 & 1 & 7 & 11 & 16 & 36 & 69 \\
6 & 0 & 1 & 0 & 15 & 15 & 10 & 37 & 78 \\
7 & 1 & 0 & 0 & 7 & 5 & 10 & 17 & 40 \\
$8+9$ & 0 & 0 & 0 & 2 & 1 & 4 & 4 & 13 \\
Total & 1 & 1 & 1 & 31 & 32 & 40 & 94 & 200 \\
\hline
\end{tabular}

A — high division: above the head of the fibula; B — intermediate division: at the height of the head of the fibula; $\mathrm{C}$ - low division: below the head of the fibula; Total — number of examined foetuses; the first letter in the first row describes the position of FDCFN on left limb, and the second one - on the right

Table 3. The relationship between symmetrical/adjacent and distant division and foetal $\operatorname{sex}\left(\chi^{2}=9.45, p=0.15\right)$

\begin{tabular}{lcccccccc}
\hline Sex & A + B & A + C & B + A & B + B & B + C & C + B & C + C & Total \\
\hline Male & 0 & 1 & 0 & 13 & 16 & 15 & 54 & 99 \\
Female & 1 & 0 & 1 & 18 & 16 & 25 & 40 & 101 \\
Total & 1 & 1 & 1 & 31 & 32 & 40 & 94 & 200
\end{tabular}

A — high division: above the head of the fibula; B — intermediate division: at the height of the head of the fibula; $\mathrm{C}$ - low division: below the head of the fibula; Total — number of examined foetuses; the first letter in the first row describes the position of FDCFN on left limb, and the second one - on the right). 
anatomy. It is based on the analysis of a small number of cases, without a division into age classes $[12,28]$.

It is worth emphasizing that the variability of the fibular nerves arouses great interest in the scientific world, as evidenced by numerous anatomical publications and clinical papers describing the relationship between the neurological complications of surgical procedures or injuries and the variability of the position of nerve trunks and branches $[1,4,6,22,32$, $37,39]$. The terminal section of the common fibular nerve trunk is particularly vulnerable to injury due to its course just above the fibula [1]. Complicated fractures or direct-acting other types of injury (blow, cut) require the implementation of surgical treatment, the success of which depends upon the anatomical competence of the performing physician in this area

For this reason, a new typology has been proposed to assess the position of FDCFN in relation to the fibula head. The head of the fibula is easily palpable in a physical examination regardless of age, and can also be easily visualised in radiological examinations. It therefore seems to be the best reference point for the final division nervus peroneus communis.

The proposed typology is partly inspired by a paper published by authors from South Africa, where the fibular tubercle was used as a landmark [7]. Interestingly, there is no such a structure in the anatomical nomenclature. The authors suspect that the described point is an incorrectly defined point fibulare, which is an anthropological determinant of the detectable fragment of apex capitis fibulae.

Based on the proposed typology it has been established that type 3, i.e. low division of the common fibular nerve into end branches, is the most common typology present in the population of the examined foetuses.

Very similar characteristics are presented by Turkish researchers [28] who analysed the final division of sciatic nerve and common fibular nerve based on 20 foetuses and showed relatively low nerve division in both cases. In the available literature based on adult material, the division of common fibular nerve usually takes place above the head of the fibula $[3,8,34]$.

The presented data support the thesis of a different location of bifurcation nervus peroneus communis in human foetuses. The cause of this phenomenon has not been clearly identified. Kurtoglu et al. [28] suggest that the different location of nervous divisions is the result of limb elongation after the end of foetal development. This process affects the fascia and can thus modify the position of important anatomical points such as the final division of the common fibular nerve. On the other hand, Kołaczkowski and Stachura [26] suggest that the "climbing" of nervous divisions may be caused by a process of physical activity that significantly modifies the ratio between the length of the tendon and the length of the muscle belly by shortening the belly and lengthening the tendon, which hypothetically is supposed to change the position of the nervous branches.

Most importantly, this work aimed to demonstrate the presence of nervus peroneus superficialis accessorius. The available literature very rarely indicates the presence of an additional branch of the common fibular nerve [20,35]. This additional branch occurred among as many as $30 \%$ of the examined foetuses, of which as much as $50 \%$ of the cases appeared on both sides. Similar observations can be found in a study by Domagała et al. [12], who also indicate the presence of an additional branch of the common fibular nerve, which penetrates the anterior compartment of leg in $12 \%$ of examined foetuses. The authors defined this nerve as nervus peroneus accessorius because of its origin, which makes it impossible to define this additional branch as an element originating from nervus peroneus superficialis or nervus peroneus profundus. The sample was much less numerous, so it is probable that this frequency would increase as the size of the examined cohort increases. While these branches are fascinating for anatomists, they are also of great clinical importance. Their unusual localisation may lead to unpredictable complications, especially as it is likely that, in addition to the sensory fibres, they may also conduct motor fibres to musculus peroneus tertius [14] or musculus extensor digitorum brevis [30].

\section{Acknowledgements}

The authors of the paper thank Alina Proniewicz, MSc for help in choosing foetuses, Joanna Grzelak, MSci, PhD for statistical analysis and Victoria Tarkowski, BA from Toronto, Canada for linguistic correction.

The presented research results, carried out within the framework of the topic according to the register in the $S$ system with the number $A 350.21 .070$, were financed from the subsidy granted by the Minister of Science and Higher Education.

Conflict of interest: None declared 


\section{REFERENCES}

1. Aigner $F$, Longato $S$, Gardetto $A$, et al. Anatomic survey of the common fibular nerve and its branching pattern with regard to the intermuscular septa of the leg. Clin Anat. 2004; 17(6): 503-512, doi: 10.1002/ca.20007, indexed in Pubmed: 15300871.

2. Alentorn-Geli E, Stuart JJ, James Choi JH, et al. Posterolateral portal tibial tunnel drilling for posterior cruciate ligament reconstruction: technique and evaluation of safety and tunnel position. Knee Surg Sports Traumatol Arthrosc. 2017; 25(8): 2474-2480, doi: 10.1007/s00167015-3958-0, indexed in Pubmed: 26718637.

3. Arora AK, Abrol S, Verma P. An anomalous variation in the division pattern of the common peroneal nerve. Int J Appl Basic Med Res. 2011; 1(2): 118-119, doi: 10.4103/2229516X.91159, indexed in Pubmed: 23776791.

4. Baima J, Krivickas L. Evaluation and treatment of peroneal neuropathy. Curr Rev Musculoskelet Med. 2008; 1(2): 147-153, doi: 10.1007/s12178-008-9023-6, indexed in Pubmed: 19468889.

5. Bogacka U, Dziedzic D, Komarnitki I, et al. Anatomy of the long peroneal muscle of the leg. Folia Morphol. 2017; 76(2): 284-288, doi: 10.5603/FM.a2016.0054, indexed in Pubmed: 27714727.

6. Bowley MP, Doughty CT. Entrament Neuroathies of the Lower Extremity. Vol. 103. Medical Clinics of North America 2019: 371-382.

7. Chetty $D$, Pillay $P$, Lazarus $L$, et al. The common fibular nerve (and its branches) in fetuses. Int J Morphol. 2014; 32(2): 455-460, doi: 10.4067/s0717-95022014000200013.

8. Dellon AL, Ebmer J, Swier P. Anatomic variations related to decompression of the common peroneal nerve at the fibular head. Ann Plast Surg. 2002; 48(1): 30-34, doi: 10.1097/00000637-200201000-00004, indexed in Pubmed: 11773727.

9. Domagała Z, Dąbrowski P, Kurlej W, et al. The sequence of lanugo pattern development on the trunk wall in human fetuses. Adv Clin Exp Med. 2017; 26(6): 967-972, doi: 10.17219/acem/61440, indexed in Pubmed: 29068598.

10. Domagała Z, Dąbrowski P, Porwolik M, et al. Is the secular trend reflected in early stages of human ontogenesis? Anthropol Rev. 2014; 77(1): 77-86, doi: 10.2478/anre2014-0007.

11. Domagała Z, Gworys B, Kreczyńska B, et al. contribution to the discussion concerning the variability of the third peroneal muscle: An anatomical analysis on the basis of foetal material. Folia Morphol. 2006; 65(4): 329-336, indexed in Pubmed: 17171612.

12. Domagała Z, Gworys B, Porwolik K. Preliminary assessment of anatomical variability of nervus peroneus superficialis in the foetal period. Folia Morphol. 2003; 62(4): 401-403, indexed in Pubmed: 14655126.

13. Dudek K, Kędzia W, Kędzia E, et al. Mathematical modelling of the growth of human fetus anatomical structures. Anat Sci Int. 2017; 92(4): 521-529, doi: 10.1007/s12565016-0353-y, indexed in Pubmed: 27393150.

14. Dudek K, Nowakowska-Kotas M, Kędzia A. Mathematical models of human cerebellar development in the fetal period. J Anat. 2018; 232(4): 596-603, doi: 10.1111/ joa.12767, indexed in Pubmed: 29315634.
15. Gawlikowska-Sroka A, Dabrowski P, Szczurowski J, et al. Influence of physiological stress on the presence of hypoplasia and fluctuating asymmetry in a medieval population from the village of Sypniewo. Int J Paleopathol. 2017; 19: 43-52, doi: 10.1016/j.ijpp.2017.10.002, indexed in Pubmed: 29198399.

16. Giannakopoulou C, Korakaki E, Hatzidaki E, et al. Peroneal nerve palsy: a complication of umbilical artery catheterization in the full-term newborn of a mother with diabetes. Pediatrics. 2002; 109(4): e66, doi: 10.1542/ peds.109.4.e66, indexed in Pubmed: 11927739.

17. Gworys B, Domagala Z. The typology of the human fetal lanugo on the thorax. Ann Anat. 2003; 185(4): 383-386, doi: 10.1016/S0940-9602(03)80066-3, indexed in Pubmed: 12924478.

18. Gworys B, Jeka S, Brukiewa R, et al. Dinámica de crecimiento del estómago en el período fetal humano: un estudio post-mortem. Int J Morphol. 2012; 30(2): 461-6.

19. Hall MP, Ryzewicz M, Walsh PJ, et al. Risk of iatrogenic injury to the peroneal nerve during posterolateral femoral tunnel placement in double-bundle anterior cruciate ligament reconstruction. Am J Sports Med. 2009; 37(1): 109-113, doi: 10.1177/0363546508324177, indexed in Pubmed: 18952904.

20. Infante E, Kennedy WR. Anomalous branch of the peroneal nerve detected by electromyography. Arch Neurol. 1970; 22(2): 162-165, doi: 10.1001/archneur.1970.00480200068007, indexed in Pubmed: 5409772.

21. Jenkins $M J$, Farhat $M, H$ wang $P$, et al. The distance of the common peroneal nerve to the posterolateral structures of the knee. J Arthroplasty. 2016; 31(12): 2907-2911, doi: 10.1016/j.arth.2016.05.005, indexed in Pubmed: 27267229.

22. Kang J, Yang P, Zang Q, et al. Traumatic neuroma of the superficial peroneal nerve in a patient: a case report and review of the literature. World J Surg Oncol. 2016; 14(1): 242, doi: 10.1186/s12957-016-0990-6, indexed in Pubmed: 27613606.

23. Kedzia A, Andrzejak R, Dudek K, et al. Analysis of human scapula morphometry in the fetal period. Adv Clin Exp Med. 2009; 18(3): 197-204.

24. Kedzia A, Woźniak W. The long colic nerves in human fetuses. I. Macroscopic studies. Folia Morphol. 1992; 51(3): 225-40, indexed in Pubmed: 1339778.

25. Khan AA, Asari MA, Pasha MA. The sciatic nerve in human cadavers: high division or low formation? Folia Morphol. 2016; 75(3): 306-310, doi: 10.5603/FM.a2015.0130, indexed in Pubmed: 26711654.

26. Kołaczkowski Z, Stachura D. Antropomorfologia mięśnia piszczelowego przedniego w ontogenezie człowieka. Przegl Antrop. 1974; 40: 77-84.

27. Kulus M, Dąbrowski P. How to calculate the age at formation of Harris lines? A step-by-step review of current methods and a proposal for modifications to Byers' formulas. Archaeol Anthropol Sci. 2019; 11(4): 1169-1185, doi: 10.1007/s12520-018-00773-5.

28. Kurtoglu Z, Aktekin M, Uluutku MH. Branching patterns of the common and superficial fibular nerves in fetus. Clin Anat. 2006; 19(7): 621-626, doi: 10.1002/ca.20235, indexed in Pubmed: 16302233. 
29. Mathis J, Raio L, Baud D. Fetal laser therapy: applications in the management of fetal pathologies. Prenat Diagn. 2015; 35(7): 623-636, doi: 10.1002/pd.4587, indexed in Pubmed: 25736523.

30. Murad H, Neal P, Katirji B. Total innervation of the extensor digitorum brevis by the accessory deep peroneal nerve. Eur J Neurol. 1999; 6(3): 371-373, doi: 10.1046/j.14681331.1999.630371.x, indexed in Pubmed: 10210922.

31. Nizankowski C, Ziółkowski M. Studies on the sciatic nerve course in man in the fetal period. Folia Morphol. 1979; 38(4): 481-488, indexed in Pubmed: 317585.

32. Poage $C$, Roth $C$, Scott $B$. Peroneal nerve palsy: evaluation and management. J Am Acad Orthop Surg. 2016; 24(1): 1-10, doi: 10.5435/JAAOS-D-14-00420, indexed in Pubmed: 26700629.

33. Popkov A, Aranovich A, Popkov D. Prevention of recurrence of tibia and ankle deformities after bone lengthening in children with type II fibular hemimelia. Int Orthop. 2015; 39(7): 1365-1370, doi: 10.1007/s00264-015-2752-4, indexed in Pubmed: 25832175.

34. Rausch V, Hackl M, Oppermann J, et al. Peroneal nerve location at the fibular head: an anatomic study using 3D imaging. Arch Orthop Trauma Surg. 2019; 139(7): 921-926, doi: 10.1007/ s00402-019-03141-7, indexed in Pubmed: 30737594.

35. Reimann R. [Accessory peroneal nerves in man]. Anat Anz. 1984; 155(1-5): 257-267, indexed in Pubmed: 6721189

36. Senes FM, Campus R, Becchetti F, et al. Sciatic nerve injection palsy in the child: early microsurgical treatment and long-term results. Microsurgery. 2009; 29(6): 443-448, doi: 10.1002/micr.20632, indexed in Pubmed: 19306387.

37. Tomaszewski KA, Graves MJ, Henry BM, et al. Surgical anatomy of the sciatic nerve: A meta-analysis. J Orthop Res. 2016; 34(10): 1820-1827, doi: 10.1002/jor.23186, indexed in Pubmed: 26856540.

38. Tomaszewski KA, Graves MJ, Vikse J, et al. Superficial fibular nerve variations of fascial piercing: A meta-analysis and clinical consideration. Clin Anat. 2017; 30(1): 120-125, doi: 10.1002/ca.22741, indexed in Pubmed: 27271092.

39. Tomaszewski KA, Roy J, Vikse J, et al. Prevalence of the accessory deep peroneal nerve: A cadaveric study and meta-analysis. Clin Neurol Neurosurg. 2016; 144: 105-111, doi: 10.1016/j.clineuro.2016.03.026, indexed in Pubmed: 27038872.

40. Wozniak S, Pytrus T, Kobierzycki C, et al. The large intestine from fetal period to adulthood and its impact on the course of colonoscopy. Ann Anat. 2019; 224: 17-22, doi: 10.1016/j. aanat.2019.02.004, indexed in Pubmed: 30914345.

41. Yacub JN, Rice JB, Dillingham TR. Nerve injury in patients after hip and knee arthroplasties and knee arthroscopy. Am J Phys Med Rehabil. 2009; 88(8): 635-41; quiz 642, doi: 10.1097/PHM.0b013e3181ae0c9d, indexed in Pubmed: 19620828.

42. Ziółkowski M, Gworys B, Kurlej W. Estimation of fetal age on the basis of certain measurements and ossification of the sternum. Folia Morphol. 1988; 47(1-4): 145-151, indexed in Pubmed: 3267621. 